\title{
Meningkatkan Keterampilan Membuat Serbet Gantung Melalui Video Tutorial Bagi Anak Tunagrahita Ringan
}

\author{
Mela Nofresna ${ }^{1 *}$, Irdamurni ${ }^{2}$ \\ ${ }^{1,2}$ Pendidikan Luar Biasa, Universitas Negeri Padang, Indonesia
}

Corresponding Author. E-mail: ${ }^{1 *}$ melanofresna0411@gmail.com, ${ }^{2}$ irdamurni@fip.unp.ac.id

Published: 01/10/2021

\begin{abstract}
Abstrak
Penelitian ini dilatarbelakangi oleh permasalahan seorang anak tunagrahita ringan kelas $X$ yang mengerjakan keterampilan membuat serbet gantung yang selalu salah atau tidak rapi sehingga perlu adanya pengajaran untuk meningkatkan keterampilan anak tunagrahita agar mahir dalam membuat serbet gantung melalui video tutorial agar bisa menjadi bekal anak dimasa yang akan datang dan dapat berkompetensi dalam dunia pekerjaan. Tujuan dari penelitian ini adalah untuk membuktikan apakah video tutorial dapat meningkatkan keterampilan membuat serbet gantung bagi anak tunagrahita ringan kelas X di SLB Muhammadiyah Pauh IX Padang. Jenis penelitian yang digunakan penelitian eksperimen dengan pendekatan Single Subject Research (SSR) desain A-B-A yang mana pada kondisi baseline (A1) dilaksanakan 4 kali pengamatan, intervensi (B) 8 kali pengamatan, dan baseline (A2) 4 kali pengamatan. Proses mengumpulkan data dilaksanakan dengan teknik observasi langsung dan tes perbuatan menggunakan alat pengumpulan data berupa instrumen tes perbuatan. Kemudian data dianalisis dengan teknik analisis visual grafik. Berdasarkan analisis data dari 3 kondisi selama 16 kali pertemuan, pada kondisi baseline (A1) diperoleh hasil 45,45\%, 45,45\%, 45,45\%, 45,45\%. Kondisi intervensi (B) diperoleh hasil 68,18\%, 77,27\%, 63,63\%, 90,90\%, 90,90\%, 95,45\%, 95,45\%, 95,45\%. Pada kondisi baseline (A2) diperoleh hasil 95,45\%, 95,45\%, 95,45\%, 95,45\%. Dengan demikian, hasil dari penelitian menyatakan bahwa penggunaan video tutorial dapat menigkatkan keterampilan membuat serbet gantung bagi anak tunagrahita ringan.
\end{abstract}

Kata Kunci: Keterampilan vokasional, serbet gantung, video tutorial, tunagrahita ringan

\begin{abstract}
This research is motivated by the problem of a mild mentally retarded child in class $X$ who works on the skills of making hanging napkins which are always wrong or untidy so that there is a need for teaching to improve the skills of mentally retarded children so that they are proficient in making hanging napkins through video tutorials so that they can be a provision for children in the future. and can be competent in the world of work. The purpose of this study was to prove whether video tutorials can improve the skills of making hanging napkins for mild mentally retarded children in grade $X$ at SLB Muhammadiyah Pauh IX Padang. The type of research used is experimental research with a Single Subject Research (SSR) approach with ABA design which in the baseline condition (A1) carried out 4 observations, intervention (B) 8 observations, and baseline (A2) 4 observations. The process of
\end{abstract}


collecting data is carried out by direct observation techniques and action tests using data collection tools in the form of action test instruments. Then the data were analyzed by using visual graph analysis techniques. Based on data analysis from 3 conditions for 16 meetings, thecondition baseline (A1) obtained results of $45.45 \%, 45.45 \%, 45.45 \%, 45.45 \%$. Thecondition intervention (B) resulted in $68.18 \%, 77.27 \%, 63.63 \%, 90.90 \%, 90.90 \%, 95.45 \%, 95.45 \%, 95.45 \%$. In thecondition baseline (A2), the results obtained are $95.45 \%, 95.45 \%, 95.45 \%, 95.45 \%$. Thus, the results of the study state that the use of video tutorials can improve the skills of making hanging napkins for children with mild mental retardation.

Keywords: Vocational skills, hanging napkins, video tutorials,mental retardation

Pendahuluan

Ketrampilan merupakan kemampuan dalam melakukan aktifitas untuk menyelesaikan suatu tugas. Keterampilan diberikan pada seseorang semenjak masih kecil sehingga mampu menghadapi segala permasalahan hidup dan dapat melakukan segala aktifitas secara lebih terampil dan cekatan (Ningsih, 2014).

Pembelajaran keterampilan yang diajarkan guru disekolah melalui bimbingan dan kesempatan dapat membantu siswa belajar mengembangkan dan menciptakan suatu karya dengan kemampuan yang dimilikinya. Disekolah anak bukan hanya dibekali dengan ilmu pengetahuan saja namun juga dibekali dengan pembelajaran keterampilan. Keterampilan diberikan kepada semua siswa tanpa terkecuali dengan siswa karakteristik tunagrahita.

Menurut (Sumekar, 2019) Anak tunagrahita atau anak dengan gangguan intelektual adalah anak yang secara nyata mengalami hambatan dan keterlebalakangan perkembangan mental intelektual jauh di bawah rata-rata yang menyebabkan anak mengalami kesulitan dalam mengerjakan tugas-tugas akademik, komunikasi maupun sosial sehingga memerlukan layanan dan pendidikan khusus.

Anak tunagrahita dibagi menjadi 4 kategori, salah satunya yaitu tunagrahita ringan atau disebut juga dengan tunagrahita mampu didik. Siswa tunagrahita ringan memiliki IQ berkisar antara 50-70 atau 75 (Irdamurni, 2019).
Untuk mengembangkan potensi yang dimiliki oleh anak tunagrahita guru dapat memberikan pembelajaran keterampilan disekolah yaitu keterampilan vokasional.

Berdasarkan studi pendahuluan di SLB Muhammadiyah Pauh IX Padang, peneliti menemukan 1 orang siswa berinisial $\mathrm{MH}$ di kelas $\mathrm{X}$ dengan karakterisitk tunagrahita ringan. Peneliti melakukan observasi atau pengamatan saat proses pembelajaran keterampilan berlangsung di rumah siswa.

Guru memberikan pembelajaran melalui metode latihan, pendidik secara langsung memberi arahan untuk perserta didik agar diikuti. Metode latihan digunakan guru setiap mengajarkan keterampilan kepada siswa tunagrahita pada proses pembelajaran.

Keterampilan yang diberikan guru pada waktu itu ialah keterampilan menjahit membuat serbet gantung. Proses pembelajaran diulang- ulang oleh guru agar siswa mampu membuat serbet gantung secara mandiri. Guru mengajarkan keterampilan membuat serbet gantung menggunakan metode latihan dengan tujuan pembelajaran akan tercapai, akan tetapi siswa belum dapat membuat serbet gantung secara mandiri.

Dari hasil pengamatan asesmen yang dilakukan oleh peneliti siswa tidak terhambat untuk motorik halus ini dibuktikan dengan nilai asesmen motorik halus dimana siswa sudah mampu menggenggam benda, menjahit jelujur, dan melipat kain. Akan tetapi siswa kesulitan 
dalam memasukkan benang kedalam jarum, dalam hal menggunting dan menjahit dengan menggunakan tangan siswa sudah dapat melakukan dengan bimbingan guru walaupun hasilnya kurang rapi.

Peneliti tertarik meningkatkan kemampuan belajar siswa membuat serbet gantung dan membangkitan semangat belajar siswa. Dalam membuat serbet gantung bahan yang digunakan adalah handuk kecil, selang, renda, dan juga pita kawat. Ketika memberi pelajaran ketrampilan biasanya mengajarkan dengan metode latihan, agar menghasilkan suatu yang baru keterampilan ini dapat diberikan menggunakan video tutorial.

$$
\text { Guru menjelaskan bahwa }
$$

pembelajaran keterampilan membuat serbet gantung melalui video tutorial belum pernah dicobakan kepada siswa. Peneliti tertarik menggunakan video tutorial dikarenakan siswa memiliki hp android dan siswa dapat mengoperasikan hp nya dengan baik.

Keterampilan serbet gantung sudah pernah diajarkan oleh guru kepada siswa dengan menggunakan metode latihan, alat dan bahan yang digunakan terdiri atas handuk, kain perca, busa, gunting, benang, dan jarum penjahit. Serbet gantung yang pernah diajarkan oleh guru dan yang akan peneliti ajarkan memiliki perbedaan dari segi bahan dan juga dalam proses pembuatannya.

Serbet gantung adalah salah satu keterampilan yang memiliki nilai jual yang dapat dijual dipasaran. Dari segi penjualan dipasaran serbet gantung termasuk salah satu barang yang banyak diminati dan dibeli oleh masyarakat terutama dikalangan ibuibu. Pemasaranya pun tidak hanya ada ditoko-toko alat perlengkapan dapur, tetapi juga dipasarkan di mall-mall besar dan juga banyak dijual melalui situs online. Bentuknya pun beranekaragam dengan model dan motif yang berbeda-beda dan dibuat semenarik mungkin, semakin bagus bahan yang digunakan dan juga modelnya maka semakin tinggi pula nilai jualnya dipasaran. Guru- guru dapat membantu siswa nantinya mempromosikan dan menjual serbet gantung yang telah dibuat oleh siswa, seperti yang sama-sama diketahui bahwa pada zaman sekarang kita tidak terlepas dari media sosial.

Serbet gantung yang dibuat siswa nantinya dapat dipromosikan melalui media sosial oleh guru. Untuk disekolah sendiri penjualannya dapat dibantu dengan caa meletakkanya dikoperasi dan kantin sekolah. Serbet gantung itu nantinya juga bisa dipromosikan kepada tamu yang datang kesekolah oleh pihak sekolah. Dalam proses pembuatan serbet gantung bahan dan alat yang digunakan juga tidak sulit untuk didapatkan, bahan yang digunakan tergantung model yang akan dibuat. Membuat serbet gantung sendiri nantinya juga akan membantu melatih motorik anak.

Serbet gantung berfungsi sebagai alat untuk mengeringkan tangan ketika selesai bekerja didapur. Bentuknya yang lucu dan juga bisa digantung membuat ibuibu yang selesai memasak dapat menggunakannya secara langsung didapur. Serbet gantung sebenarnya sama dengan serbet atau lap tangan lainnya akan tetapi karena adanya sedikit modifikasi pada desain membuat serbet gantung menjadi lebih menarik untuk digunakan.

Pembuatan serbet gantung dapat dilaksanakan melalui video tutorial. mempermudah siswa belajar dalam proses pembuatannya. Media video tutorial akan lebih menarik perhatian siswa dalam proses pembelajaran karena informasi yang didapat bersifat suara serta gambar yang bisa dilihat dan didengar siswa dengan menggunakan laptop handphone.

Manfaat dari penggunaan video tutorial ini adalah siswa dapat mengulang pembelajaran sendiri dirumah tanpa bimbingan dari guru, mengingat siswa dapat menggunakan handphonenya secara 
mandiri. Media video tutorial yang akan diterapkan kepada siswa berisi tentang langkah- langkah pembuatan serbet gantung.

\section{Metode}

Penelitian menggunakan metode eksperimen yang berbentuk Single Subject Research (SSR). Desain penelitian ini yaitu A-B-A, ditujukan untuk meningkatkan keterampilan membuat serbet gantung bagi anak tunagrahita ringan. Eksperimen ialah metode untuk menemukan pengaruh perlakuan mengenai perlakuan yang lain didalam kondisi yang terkendali (Sugiyono, 2017).

Desain dari metode Single Subject Research (SSR) yang digunakan berbentuk desain A-B-A. Kondisi A1 adalah phase baseline kemampuan awal sebelum diberikan perlakuan (intervensi). B (intervensi) adalah kemampuan selama diberikan perlakuan (intervensi). A2 adalah phase baseline atau mengamati kemampuan subjek dengan tidak lagi memperoleh (intervensi).

Pada penelitian ini terdiri atas 2 variabel, variabel terikatnya ialah ketrampilan membuat serbet gantung. Sedangkan variabel bebasnya ialah media video tutorial. Subjek penelitian adalah anak tunagrahita ringan berinisial $\mathrm{MH}$, berjenis kelamin laki-laki, kelas $\mathrm{X}$ di SLB Muhammadiyah Pauh IX Padang.

Teknik pengumpulan data dari penelitian ini yaitu tes perbuatan serta alat yang digunakan untuk pengumpulan data berupa instrument tes perbuatan mengenai langkah-langkah pembuatan keterampilan serbet gantung. Untuk penilaian dari masing-masing langkah-langkah yang benar, akan diberi skor 1 dan jika tidak bisa mengikuti langkah-langkah pembuatan maka akan diberi skor 0 . Kemudian data yang diperoleh dipindahkan kedalam grafik, lalu dianalisis berdasarkan komponen pada setiap fase baseline dan intervensi. Data dianalisis dengan dua tahapan yaitu menganalisis data dalam kondisi serta antar kondisi.

\section{Hasil dan Pembahasan}

Penelitian ini bertujuan membuktikan apakah media video tutorial dapat meningkatkan keterampilan membuat serbet gantung bagi anak tunagrahita ringan. Penelitian ini dilakukan melalui ters perbuatan yaitu dengan mengamati kemampuan anak dalam mengikuti langkah-langkah membuat serbet gantung pada setiap kali pertemuan.

Penelitian dilaksanakan selama 16 kali pertemuan dalam 3 kondisi yaitu pada kondisi baseline (A1) atau kemampuan anak sebelum diberi perlakuan, dilaksanakan 4 kali pertemuan dengan persentase $45,45 \%$, 45,45\%, 45,45\%, 45,45\%. Pada kondisi intervensi (B) atau kemampuan anak saat menggunakan video tutorial, dilakukan sebanyak 8 kali pertemuan dengan persentase $68,18 \%, \quad 77,27 \%, 63,63 \%$, $90,90 \%, 90,90 \%, 95,45 \%, 95,45 \%, 95,45 \%$. Kemudian (A2) dilaksanakan 4 kali pertemuan persentase $95,45 \%, 95,45 \%$, $95,45 \%, 95,45 \%$.

Berdasarkan pengamatan dari 3 kondisi tersebut, dapat diketahui bahwa kemampuan anak mengalami peningkatan saat diberikan intervensi dan setelah diberikan intervensi.

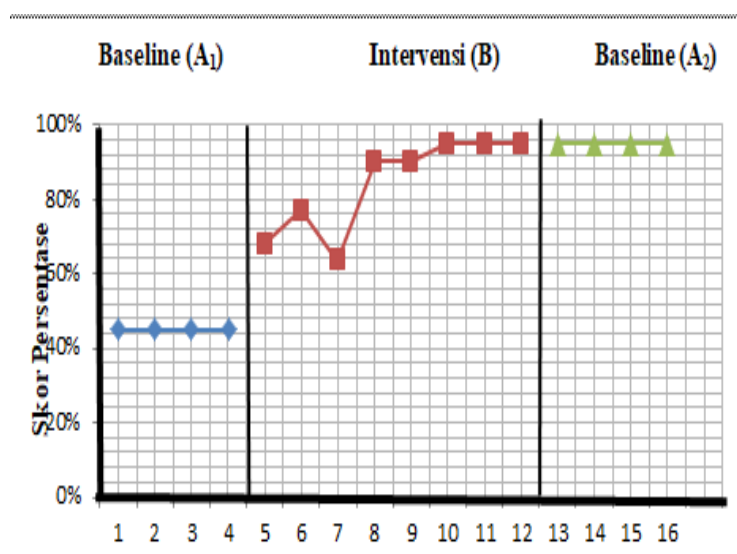

Grafik 1. Rekapitulasi Keterampilan Membuat Serbet Gantung dalam kondisi $A 1-B-A 2$ 
Dari grafik diatas diketahui (A1) dilakukan sebanyak 4 kali pertemuan dengan persentase atau perolehan skor stabil dari pengamatan ke-1 sampai dengan pengamatan ke-4 dengan perolehan skor 45,45\%. Pada intervensi dilaksanakan pengamatan 8 kali, diperoleh skor stabil di pertemuan ke-10 sampai dengan pertemuan ke-12 dengan perolehan skor $95,45 \%$. Setelah melakukan intervensi lanjut pada tahap baseline (A2), pengamatan dilakukan sebanyak 4 kali pertemuan dengan perolehan skor stabil pada pertemuan ke-13 sampai pertemuan ke-16 yaitu dengan perolehan skor $95,45 \%$.

Adapun untuk mengetahui ada tidaknya pengaruh intervensi bagi target behavior dapat dilihat dari hasil olah data didalam kondisi serta di antar kondisi. Berdasarkan hasil analis dalam kondisi, diperoleh panjang kondisi pada baseline (A1) selama 4 kali, panjang kondisi intervensi selama 8 kali serta panjang kondisi pada baseline (A2) selama 4 kali.

Dilihat dari estimasi kecenderungan arah menunjukkan pada kondisi A1 tidak terjadi perubahan $(=)$, kondisi $B$ terjadi peningkatan (+), dan pada kondisi A2 tidak terjadi perubahan. Berdasarkan kecenderungan stabilitas diperoleh pada baseline (A1) dengan mean level 45,45\%, batas atas $48,85 \%$, batas bawah $42,05 \%$, rentang stabilitas 6,8 persentase $100 \%$ (stabil). Sedangkan pada intervensi (B) dengan mean level $84,65 \%$, batas atas $91,8 \%$, batas bawah $77,5 \%$, rentang stabilitas 14,31, persentase $25 \%$ (tidak stabil). Pada baseline (A2) dengan mean level $95,45 \%$, batas atas $102,6 \%$, batas bawah $88,3 \%$, rentang stabilitas 14,31 persentase $100 \%$ (stabil).

Selanjutnya pada jejak data kondisi A1 tidak terjadi perubahan, kondisi $\mathrm{B}$ terjadi peningkatan dan A2 tidak terjadi perubahan. Selanjutnya pada level perubahan diperoleh A1 sebesar $0, \quad$ B sebesar 27,27 dan A2 sebesar 0 .
Tabel 1. Rekapitulasi Hasil Analisis Dalam Kondisi

\begin{tabular}{|c|c|c|c|c|}
\hline No. & Kondisi & A1 & B & A2 \\
\hline 1. & Panjang Kondisi & 4 & 8 & 4 \\
\hline 2. & $\begin{array}{l}\text { Estimasi } \\
\text { Kecenderu-ngan } \\
\text { Arah }\end{array}$ & $(=)$ & $(+)$ & $(=)$ \\
\hline 3. & $\begin{array}{l}\text { Kecenderu-ngan } \\
\text { Stabilitas }\end{array}$ & $\begin{array}{c}100 \% \\
\text { (stabil) }\end{array}$ & $\begin{array}{l}25 \% \\
\text { (tidak } \\
\text { stabil) } \\
\end{array}$ & $\begin{array}{c}100 \% \\
\text { (stabil) }\end{array}$ \\
\hline 4. & $\begin{array}{l}\text { Kecenderu-ngan } \\
\text { Jejak Data }\end{array}$ & $(=)$ & $(+)$ & $(=)$ \\
\hline 5. & $\begin{array}{l}\text { Level Stabilitas } \\
\text { dan Rentang }\end{array}$ & $\begin{array}{r}\text { Stabil } \\
45.45 \% \\
45,45 \% \\
\end{array}$ & \begin{tabular}{|c|} 
Variabel \\
$68,18 \%$ - \\
$95,45 \%$
\end{tabular} & $\begin{array}{c}\text { Variabel } \\
95,45 \% \text { - } \\
95,45 \%\end{array}$ \\
\hline 6. & Level Perubahan & $\begin{array}{c}45,45- \\
45,45 \\
=0 \\
(=)\end{array}$ & $\begin{array}{c}95,45 \\
-68 \\
18= \\
27,27 \\
(+)\end{array}$ & $\begin{array}{c}95,45 \\
- \\
95,45 \\
=0 \\
(=)\end{array}$ \\
\hline
\end{tabular}

Berdasarkan hasil analisis antar kondisi, diperoleh banyak variabel yang diubah berjumlah 1 variabel yaitu keterampilan membuat serbet gantung melalui video tutorial bagi anak tunagrahita ringan. Dapat dilihat pada perubahan kecenderungan arah menunjukkan A1 tidak terjadi perubahan, pada kondisi $B$ terjadi peningkatan dan A2 tidak terjadi perubahan. Maka dari itu, pemberian intervensi dengan video tutorial dalam keterampilan membuat serbet gantung memiliki pengaruh positif bagi variabel yang diubah. Selanjutnya, perubahan kecenderungan disabilitas untuk kondisi A1 dalam keterampilan membuat serbet gantung masih rendah dengan perolehan persentase yaitu: 45,45\%, 45,45\%, 45,45\%, $45,45 \%$. Sedangkan pada kondisi B dengan penggunaan video tutorial mengalami peningkatan dengan perolehan persentase yaitu: $68,18 \%, 77,27 \%, 63,63 \%, 90,90 \%$, $90,90 \%, \quad 95,45 \%, \quad 95,45 \%, \quad 95,45 \%$. Selanjutnya pada kondisi A2 dengan tidak lagi diberikan perlakuan juga mengalami 
peningkatan dengan peroleh persentase yaitu: $95,45 \%, 95,45 \%, 95,45 \%, 95,45 \%$. Berdasarkan level perubahan dapat dilihat bahwa $A 1 / B$ mengalami tingkat perubahan dengan nilai 22,73 , dan pada $B / A 2$ juga mengalami tingkat perubahan dengan nilai $27,27 \%$. Kemudian dari persentase overlap A1 diperoleh hasil $0 \%$ dan $\mathrm{A} 2$ diperoleh hasil $25 \%$.

Tabel 2. Kondisi Keseluruhan

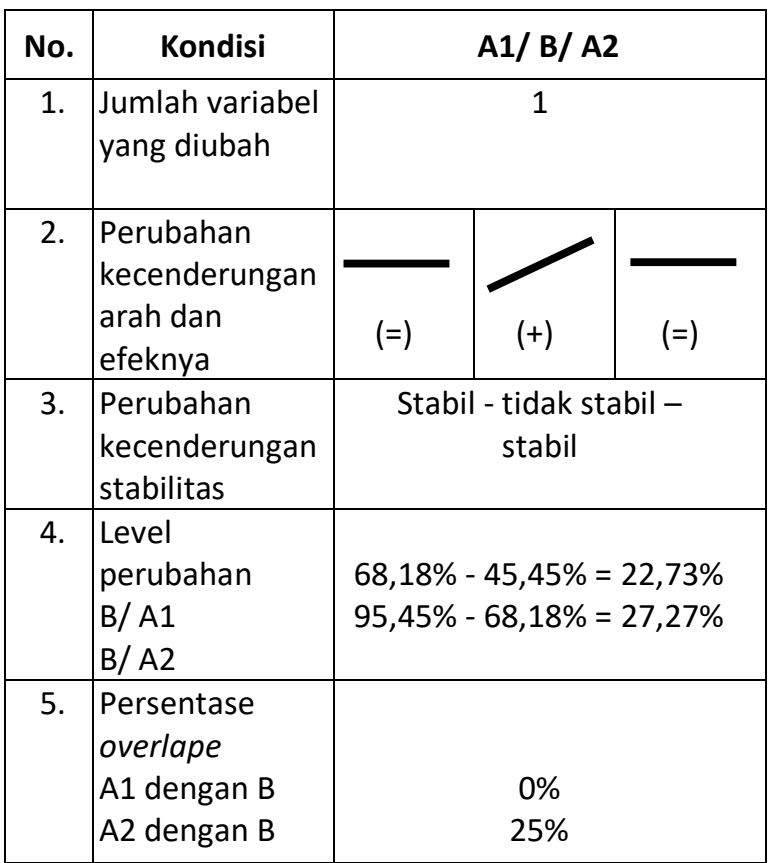

\section{Simpulan}

Berdasarkan hasil penelitian yang telah dianalisis, dapat disimpulkan bahwa penggunaan media video tutorial dapat meningkatkan keterampilan membuat serbet gantung bagi anak tunagrahita ringan. Dari hasil analisis data yang telah dilakukan baik analisis dalam kondisi dan analisis antar kondisi menunjukkan adanya peningkatan kemampuan anak dalam membuat keterampilan serbet gantung disetiap kondisi.

\section{Daftar Pustaka}

[1] Irdamurni. (2019). Pendidikan Inklusif: Solusi dalam Mendidik Anak Berkebutuhan Khusus. Padang: Prenadamedia Group.

[2] Ningsih, S. (2014.). Peningkatan Keterampilan Berbicara melalui Metode Bercerita Siswa Kelas III SD Negeri 1 Beringin Jaya Kecamatan Bumi Raya Kabupaten Morowali. 2(4), 243-256.

[3] Riyanto, S. \& Hatmawan, A. A. (2020). Metode Riset Penelitian Kuantitatif: Penelitian di Bidang Manajemen, Teknik, Pendidikan, dan Eksperimen. Yogyakarta: DEEPUBLISH.

[4] Sugiyono. (2016). Metode Penelitian Kuantitatif, Kualitatif, dan R\&D (23rd ed.). BANDUNG: ALFABETA.

[5] Sunanto, J., Takeuchi, K., \& Nakata, H. (2005). Pengantar Penelitian dengan Subjek Tunggal. Tsukuba: CRICED University of Tsukuba.

\section{Profil Penulis}

Nama saya Mela Nofresna, saya lahir di kota Padang tanggal 4 November 1998. Sekarang saya sedang menempuh pendidikan S1 di jurusan Pendidikan Luar Biasa, Fakultas IImu Pendidikan, Universitas Negeri Padang tahun masuk 2017. Kegiatan saya saat ini yaitu sedang menyelesaikan skripsi sebagai salah salah satu syarat untuk memperoleh gelar Sarjana Pendidikan. 